\title{
Test sequence of CSF and MRI biomarkers for prediction of $A D$ in subjects with $\mathrm{MCl}$
}

Citation for published version (APA):

Vos, S., van Rossum, I. A., Burns, L., Knol, D., Scheltens, P., Soininen, H., Wahlund, L-O., Hampel, H., Tsolaki, M., Minthon, L., Handels, R., L'Italien, G., van der Flier, W. M., Aalten, P., Teunissen, C., Barkhof, F., Blennow, K., Wolz, R., Rueckert, D., ... Visser, P. J. (2012). Test sequence of CSF and MRI biomarkers for prediction of AD in subjects with MCl. Neurobiology of Aging, 33(10), 2272-2281. https://doi.org/10.1016/j.neurobiolaging.2011.12.017

Document status and date:

Published: 01/10/2012

DOI:

10.1016/j.neurobiolaging.2011.12.017

Document Version:

Publisher's PDF, also known as Version of record

Document license:

Taverne

Please check the document version of this publication:

- A submitted manuscript is the version of the article upon submission and before peer-review. There can be important differences between the submitted version and the official published version of record.

People interested in the research are advised to contact the author for the final version of the publication, or visit the DOI to the publisher's website.

- The final author version and the galley proof are versions of the publication after peer review.

- The final published version features the final layout of the paper including the volume, issue and page numbers.

Link to publication

\footnotetext{
General rights rights.

- You may freely distribute the URL identifying the publication in the public portal. please follow below link for the End User Agreement:

www.umlib.nl/taverne-license

Take down policy

If you believe that this document breaches copyright please contact us at:

repository@maastrichtuniversity.nl

providing details and we will investigate your claim.
}

Copyright and moral rights for the publications made accessible in the public portal are retained by the authors and/or other copyright owners and it is a condition of accessing publications that users recognise and abide by the legal requirements associated with these

- Users may download and print one copy of any publication from the public portal for the purpose of private study or research.

- You may not further distribute the material or use it for any profit-making activity or commercial gain

If the publication is distributed under the terms of Article $25 \mathrm{fa}$ of the Dutch Copyright Act, indicated by the "Taverne" license above, 


\title{
Test sequence of CSF and MRI biomarkers for prediction of $\mathrm{AD}$ in subjects with MCI
}

\author{
Stephanie Vos ${ }^{\mathrm{a}, *}$, Ineke van Rossum ${ }^{\mathrm{b}}$, Leah Burns ${ }^{\mathrm{c}}$, Dirk Knol ${ }^{\mathrm{d}}$, Philip Scheltens ${ }^{\mathrm{b}}$,
} Hilkka Soininen $^{\mathrm{e}}$, Lars-Olof Wahlund ${ }^{\mathrm{f}}$, Harald Hampel ${ }^{\mathrm{g}}$, Magda Tsolaki ${ }^{\mathrm{h}}$, Lennart Minthon ${ }^{\mathrm{i}}$, Ron Handels ${ }^{\mathrm{a}}$, Gilbert L'Italien ${ }^{\mathrm{c}}$, Wiesje van der Flier ${ }^{\mathrm{b}}$, Pauline Aalten ${ }^{\mathrm{a}}$, Charlotte Teunissen ${ }^{\mathrm{j}}$, Frederik Barkhof ${ }^{\mathrm{k}}$, Kaj Blennow ${ }^{1}$, Robin $\mathrm{Wolz}^{\mathrm{m}}$, Daniel Rueckert ${ }^{\mathrm{m}}$, Frans Verhey ${ }^{\mathrm{a}}$, Pieter Jelle Visser ${ }^{\mathrm{a}, \mathrm{b}}$

\author{
${ }^{a}$ Department of Psychiatry and Neuropsychology, Maastricht University, School for Mental Health and Neuroscience, Alzheimer Center Limburg, \\ Maastricht, the Netherlands \\ ${ }^{b}$ Department of Neurology, Alzheimer Center, VU University Medical Center, Amsterdam, the Netherlands \\ ${ }^{c}$ Bristol-Myers Squibb Company, Wallingford, CT, USA \\ ${ }^{d}$ Department of Epidemiology and Biostatistics, VU University Medical Center, Amsterdam, the Netherlands \\ ${ }^{e}$ Department of Neurology, University of Eastern Finland and Kuopio University Hospital, Kuopio, Finland \\ ${ }^{f}$ Department of NVS, Section of Clinical Geriatrics, Karolinska Institutet, Karolinska University Hospital, Huddinge, Sweden \\ ${ }^{g}$ Department of Psychiatry, Psychosomatic Medicine and Psychotherapy, Goethe-University, Frankfurt, Germany \\ ${ }^{h}$ Aristotle University of Thessaloniki, Memory and Dementia Center, 3rd Department of Neurology, "G Papanicolaou" General Hospital, Thessaloniki, Greece \\ ${ }^{i}$ Clinical Memory Research Unit, Department of Clinical Sciences Malmö, Lund University, Malmö, Sweden \\ ${ }^{j}$ Department of Clinical Chemistry, VU University Medical Center, Amsterdam, the Netherlands \\ ${ }^{k}$ Department of Radiology, VU University Medical Center, Amsterdam, the Netherlands \\ ${ }^{l}$ Clinical Neurochemistry Laboratory, Göteborg University, Sahlgrenska University Hospital, Mölndal, Sweden \\ ${ }^{m}$ Department of Computing, Imperial College London, London, UK
}

Received 24 May 2011; received in revised form 25 November 2011; accepted 13 December 2011

\begin{abstract}
Our aim was to identify the best diagnostic test sequence for predicting Alzheimer's disease (AD)-type dementia in subjects with mild cognitive impairment (MCI) using cerebrospinal fluid (CSF) and magnetic resonance imaging (MRI) biomarkers. We selected 153 subjects with mild cognitive impairment from a multicenter memory clinic-based cohort. We tested the CSF beta amyloid (A $\beta$ ) $1-42 /$ tau ratio using enzyme-linked immunosorbent assay (ELISA) and hippocampal volumes (HCVs) using the atlas-based learning embeddings for atlas propagation (LEAP) method. Outcome measure was progression to AD-type dementia in 2 years. At follow-up, 48 (31\%) subjects converted to AD-type dementia. In multivariable analyses, CSF A $\beta 1-42 /$ tau and HCV predicted AD-type dementia regardless of apolipoprotein E (APOE) genotype and cognitive scores. Test sequence analyses showed that CSF A $\beta 1-42 /$ tau increased predictive accuracy in subjects with normal HCV $(p<0.001)$ and abnormal HCV $(p=0.025)$. HCV increased predictive accuracy only in subjects with normal CSF A $\beta 1-42 /$ tau $(p=0.014)$. Slope analyses for annual cognitive decline yielded similar results. For selection of subjects for a prodromal AD trial, the best balance between sample size and number of subjects needed to screen was obtained with CSF markers. These results provide further support for the use of CSF and magnetic resonance imaging biomarkers to identify prodromal AD.
\end{abstract}

(C) 2012 Elsevier Inc. All rights reserved.

Keywords: Alzheimer's disease (AD); Dementia; Mild cognitive impairment (MCI); cerebrospinal fluid (CSF); A $\beta 1-42$; Tau; Magnetic resonance imaging (MRI); Volumetry; Hippocampus; Diagnostic test sequence

\footnotetext{
* Corresponding author at: Department of Psychiatry and Neuropsychology, Maastricht University, PO Box 616, 6200 MD Maastricht, the Netherlands. Tel.: +31 43 3881841; fax: +31 433884092 .

E-mail address: s.vos@maastrichtuniversity.nl (S. Vos).
}

\section{Introduction}

Diagnosis of Alzheimer's disease (AD) in the stage of mild cognitive impairment (MCI) is important in order to give patients a prognosis. Moreover, disease-modifying drugs for $\mathrm{AD}$ might be most effective in this early course of 
the disease. Several biomarkers of AD are now available that can help to identify AD pathology including abnormal levels of beta amyloid (A $\beta) 1-42$ and tau in cerebrospinal fluid (CSF; Blennow and Hampel, 2003; Hansson et al., 2009; Herukka et al., 2005; Mattsson et al., 2009; Shaw et al., 2009) and medial temporal lobe atrophy on magnetic resonance imaging (MRI; Devanand et al., 2007; Geroldi et al., 2006; Jack et al., 1999; Visser et al., 2002).

For clinical practice and for selection of subjects for prodromal $\mathrm{AD}$ trials, it is of major importance to investigate which combination of CSF and MRI biomarkers could best predict AD-type dementia in subjects with MCI. Some studies found that CSF biomarkers could best predict ADtype dementia (Bouwman et al., 2007; Eckerström et al., 2010; Galluzzi et al., 2010; Landau et al., 2010), but others studies found that MRI biomarkers were the best predictor (Ewers et al., 2010; Vemuri et al., 2009). Moreover, several studies showed that a combination of these biomarkers could predict AD-type dementia in subjects with MCI more accurately than each biomarker alone (Bouwman et al., 2007; Eckerström et al., 2010; Ewers et al., 2010; Galluzzi et al., 2010; Heister et al., 2011; Vemuri et al., 2009).

These previous studies, however, had several limitations. They had a small sample size or were performed in a highly selected research sample (Bouwman et al., 2007; Eckerström et al., 2010; Ewers et al., 2010; Galluzzi et al., 2010; Heister et al., 2011; Vemuri et al., 2009). Moreover, some studies included only subjects with amnestic MCI (aMCI) while subjects with $\mathrm{MCI}$ due to $\mathrm{AD}$ may also present as nonamnestic MCI (naMCI) (Visser et al., 2009). The use of a broad definition of $\mathrm{MCI}$ is also recommended in the new criteria for MCI due to $\mathrm{AD}$ of the National Institute on Aging and Alzheimer's Association Work Group (NIA-AA) (Albert et al., 2011).

Our aim was to identify the best combination of CSF and MRI biomarkers to predict conversion to AD-type dementia after 2 years in a large clinically representative sample of subjects with MCI, such that the number of tests could be reduced and as a consequence reduce patients' burden and costs (Hampel et al., 2011). We performed test sequence analyses of CSF and MRI measures and examined how the use of different combinations of biomarkers as inclusion criterion influenced the sample size and number of subjects required for screening for a fictive trial in prodromal AD. Although conversion to $\mathrm{AD}$-type dementia after a 2-year follow-up is a clinically relevant outcome, the potential of CSF and MRI biomarkers to identify prodromal $\mathrm{AD}$ may be underestimated as subjects may convert at longer follow-up intervals. Therefore, we additionally performed slope analyses with annual cognitive decline as outcome measure (Aisen et al., 2011).

\section{Methods}

\subsection{Subjects}

Subjects were recruited from the DESCRIPA (Development of Screening Guidelines and Clinical Criteria for Pre- dementia AD) study and the Alzheimer Center of the VU University Medical Center (VUmc). For the present study, inclusion criteria were baseline diagnosis of MCI, age $\geq 55$ years, availability of data on the CSF ratio of A $\beta 1-42$ to total tau (t-tau) and automatically measured hippocampal volumes (HCVs) on MRI, and being newly referred for assessment of cognitive complaints. Exclusion criteria were diagnosis of dementia at baseline or any other somatic, psychiatric, or neurological disorder that might have caused the cognitive impairment.

DESCRIPA is a European multicenter study performed in a memory clinic setting (Visser et al., 2008). Subjects were recruited from 6 centers, as both MRI and CSF data were only available at these centers. Of the 207 eligible subjects enrolled between 2003 and 2005 at these centers, 74 had data for both measures. The VUmc center was 1 of the DESCRIPA centers and contributed an additional sample of subjects that were seen outside the DESCRIPA inclusion period. Of the 217 additional eligible subjects that were included between 1998 and 2007 at this center, 91 had baseline data for both MRI and CSF.

Subjects for whom both MRI and CSF data were available differed from subjects for whom MRI and CSF data were not available with regard to age (69.3 vs. 71.2 years; $p<0.001$ ), Mini Mental State Examination (MMSE) score (26.6 vs. $27, p=0.019)$, and MCI type (68\% vs. $59 \%$ aMCI; $p=0.016)$ at baseline. The CSF A $\beta 1-42 /$ tau ratio and HCV were similar in both groups. The total sample size was 165 . The medical ethics committee at each center approved the study. All patients provided informed consent.

\subsection{Clinical and cognitive assessment}

Assessment of the subjects included a clinical history, medical and neurological examination, laboratory tests, functional evaluation with the Clinical Dementia Rating scale, rating scales for neuropsychiatric symptoms, scoring on the MMSE, and neuropsychological assessment (Bouwman et al., 2007; Visser et al., 2008). All data were collected by investigators who were blinded to the results of biomarker analyses. Follow-up assessment was performed annually up to 5 years. Primary outcome measure was conversion to AD-type dementia after 2 years according to the DSM-IV Diagnostic and Statistical Manual of Mental Disorders (American Psychiatric Association, 1994) and NINCDS-ADRDA (National Institute of Neurological and Communicative Disorders and Stroke-Alzheimer's Disease and Related Disorders Association) criteria (McKhann et al., 1984). Secondary outcome measure was annual cognitive decline on the MMSE and a cognitive composite score.

Baseline diagnosis of MCI was made according to the criteria of Petersen (Petersen, 2004). Raw scores on neuropsychological tests were corrected for age, education, and sex, in accordance with locally collected or published normative data and expressed as $z$-scores; the $z$-scores were used for further analysis (Visser et al., 2008). Subjects with 
a $z$-score $<-1.5 \mathrm{SD}$ on the learning measure or delayed recall of a word list learning test or equivalent memory test were classified as having aMCI $(n=102)$. Subjects with a $z$-score $<-1.5 \mathrm{SD}$ on the trail making test (TMT) Part A, TMT Part B, verbal fluency, Rey figure copy test or equivalent test but no memory impairment were classified as having naMCI ( $n=48$; see Appendix S1 [Visser et al., 2008]). The MCI subtype diagnosis was missing for 3 subjects, as they did not undergo a neuropsychological assessment. We calculated a cognitive composite score as the average $z$-score of 5 tests (learning and delayed recall score of the word learning list, TMT A and B, verbal fluency, copy figures), if scores were available for at least 3 cognitive tests (Visser et al., 2009).

\subsection{CSF analyses}

CSF was collected by lumbar puncture, centrifuged, and stored at $-80{ }^{\circ} \mathrm{C}$ in polypropylene tubes. One sample was thawed twice but analyses without this sample revealed similar results. CSF A $\beta 1-42$ and t-tau were measured using commercially available sandwich enzyme-linked immunosorbent assays (ELISAs) (Innotest $\beta$-amyloid 1-42; Innotest hTAU-Ag; Innogenetics, Ghent, Belgium), specially constructed to measure $\mathrm{A} \beta 1-42$ and t-tau (Andreasen et al., 1999; Blennow et al., 1995) by experienced technicians at the laboratory in Gothenburg for the DESCRIPA cohort and in Amsterdam for the VUmc cohort. We corrected for interlaboratory enzyme-linked immunosorbent assay differences by analyzing 33 samples at both laboratories and we adjusted VUmc values to those of DESCRIPA using the following formula: Gothenborg $=$ (SD Gothenborg/SD VUmc) $\times$ VUmc + average Gothenborg - ([SD Gothenborg/SD VUmc] $\times$ average VUmc) (Kolen and Brennan, 1995).

As a CSF measure, we used the ratio of $\mathrm{A} \beta 1-42$ to t-tau, which is the best CSF biomarker according to a recent meta-analysis (van Rossum et al., 2010) and accepted by the European Medical Agency for inclusion of subjects for prodromal AD trials (Isaac et al., 2011). The CSF ratio was dichotomized by defining a cutoff point (1.14) that could best predict AD-type dementia after 2 years based on the Youden index from a time-dependent receiver operating characteristic (ROC) curve in R (Version R 2.10.1 for Mac OS X 10.6, Vienna, Austria [R Development Core Team, 2009]) (Heagerty et al., 2000), including all subjects with CSF data in both cohorts $(n=219)$. In 5 subjects, CSF was obtained at follow-up. As these subjects had a normal CSF ratio score, they were considered to have a normal CSF score at baseline as well.

\subsection{MRI analyses}

For the DESCRIPA cohort, subjects were scanned according to the routine MRI protocol at each site (Appendix $\mathrm{S} 2$ ). Scanning was performed at 1.0 or $1.5 \mathrm{~T}$ and included a 3-dimensional T1-weighted gradient echo sequence and a fast fluid attenuated inversion recovery (FLAIR) sequence (van de Pol et al., 2009).

As measure of medial temporal lobe atrophy, we used HCV measured centrally at the Department of Computing at Imperial College London by experienced technicians, using learning embeddings for atlas propagation (LEAP) (Wolz et al., 2010). LEAP is an automated structural segmentation, performed by propagating multiple manually segmented atlas images to a diverse image set in a stepwise fashion, ensuring that image registration needed to be performed between similar images only. All labels propagated to a target image were considered together with a structures intensity distribution to estimate the final segmentation (e.g., Supplementary Fig. S1). Quality control was performed by visual inspection of the segmentation on transverse, coronal, and sagittal slices. HCVs were normalized to intracranial volume using Montreal Neurological Institute (MNI) scaling. The sum of left and right HCV was dichotomized by defining a cutoff $\left(5.3 \mathrm{~cm}^{3}\right)$ that could best predict AD-type dementia after 2 years based on the Youden index from a time-dependent ROC curve in R (R Development Core Team, 2009), including all subjects with HCV data in both cohorts $(n=339)$. In 6 subjects, MRI was performed at follow-up. As these subjects had a normal HCV score, they were considered to have a normal HCV score at baseline as well.

\subsection{APOE genotype}

Apolipoprotein E (APOE) genotype was determined by polymerase chain reaction of genomic DNA extracted from EDTA anticoagulated blood in 138 subjects. Subjects were classified as APOE- $\varepsilon 4$ carriers or noncarriers.

\subsection{Statistical analyses}

Statistical analyses were done with SPSS version 16.0 (Chicago, IL, USA) and statistical software package R version 2.10.1 (R Development Core Team, 2009). Significance was set at $p<0.05$ and $95 \%$ confidence intervals (CIs) were calculated. Differences between groups were analyzed using a $t$ test for continuous variables and $\chi^{2}$ test for categorical variables.

Univariable and multivariable logistic regression analyses were performed for dichotomized CSF and MRI markers to assess whether a combination of markers was better predictive for AD-type dementia. Sensitivity, specificity, positive predictive value, negative predictive value, Youden index (sensitivity + specificity -1 ), and odds ratio (OR) were calculated. Multivariable analyses with correction for center yielded similar findings. Therefore, we did not correct for center in the final analyses.

Change on the MMSE and cognitive composite score were assessed by use of slope analyses with mixed models. The analyses included the baseline score and available follow-up scores up to 5 years after baseline. We used an unstructured covariance structure with center as a random 
effect as this model provided the best -2 log likelihood compared with models with simpler covariance structures (Visser et al., 2009). We examined whether the slopes of cognition were different for subjects with and without abnormal CSF or MRI biomarker scores and whether the combination of both biomarkers increased predictive accuracy for cognitive decline.

Test sequence analyses were performed to investigate the added predictive value of a second biomarker for AD-type dementia or cognitive decline in specific subgroups. We identified the best test sequence of CSF A $\beta 1-42 /$ tau ratio and $\mathrm{HCV}$ assessment and visualized it using probabilitymodifying plots (Severens et al., 2001).

The relation between biomarkers, the sample size, and number of subjects required for screening, was tested for a fictive placebo-controlled $\mathrm{AD}$ drug trial targeting amyloid pathology in subjects with MCI. The number of subjects was calculated in such a way that the study could detect a relative decrease of $25 \%$ in conversion rate to AD-type dementia over a 2-year period in subjects with $\mathrm{AD}$ pathology, which was defined as an abnormal CSF A $\beta 1-42 /$ tau ratio, with a power of $90 \%$, a 2 -sided alpha of $5 \%$, a drop-out rate of $30 \%$, and equally sized treatment groups (van Rossum et al., 2010). The prevalence of abnormal biomarkers and conversion rate were based on the observed data in our study.

\section{Results}

\subsection{Sample characteristics}

One hundred fifty-three subjects had at least 1 follow-up assessment (average 3.7 years; SD $=1.4$ ). Forty-eight subjects $(31 \%)$ converted to AD-type dementia after 2 years, and 6 subjects $(4 \%)$ converted to other types of dementia and were included in the non-AD group. Subjects with at least 1 follow-up had similar baseline characteristics as those without follow-up (Supplementary Table S1).

\subsection{Predictors of AD-type dementia}

\subsubsection{Univariable predictors}

Subjects with AD-type dementia at 2-year follow-up had lower MMSE scores $(p=0.014)$, lower cognitive composite score $(p=0.009)$, lower CSF levels of A $\beta 1-42(p<$ $0.001)$, higher CSF levels of t-tau $(p<0.001)$, a lower CSF A $\beta 1-42 /$ tau ratio $(p<0.001)$, smaller HCV $(p<0.001)$, a higher frequency of APOE- $\varepsilon 4$ alleles $(p=0.011)$, and tended to have more often aMCI (75\% vs. $65 \%, p>0.10)$, compared with subjects without AD-type dementia (Table $1)$. Scores on verbal fluency $(p=0.052)$ and delayed recall $(p=0.069)$ tended to be lower for subjects who progressed to AD-type dementia compared with those who did not progress. The overall predictive accuracy (OR) was more than twice as high for the CSF A $\beta 1-42 /$ tau ratio (OR, 9.2; 95\% CI, 3.9-22; $p<0.001)$ than for HCV (OR, 3.7; 95\% CI, $1.8-7.6 ; p<0.001$, Table 2). Of the subjects without
Table 1

Baseline characteristics of subjects with MCI by outcome at 2-year follow-up

\begin{tabular}{lcc}
\hline & MCI non-AD & MCI-AD \\
\hline$n$ & 105 & 48 \\
Age, y & $68.8(7.3)$ & $70.4(7.2)$ \\
Female, $n(\%)$ & $43(41.0)$ & $24(50.0)$ \\
aMCI, $n(\%)$ & $67(65.0)$ & $35(74.5)$ \\
Years of education & $10.7(3.2)$ & $11.2(3.0)$ \\
MMSE & $26.9(2.6)$ & $25.8(2.8) * *$ \\
Delayed recall, $z$-score & $-1.34(1.1)$ & $-1.76(1.0)$ \\
Learning, $z$-score & $-1.15(1.1)$ & $-1.44(1.1)$ \\
Verbal fluency, $z$-score & $-0.66(1.1)$ & $-1.04(0.9)$ \\
TMT A, $z$-score & $-0.44(1.6)$ & $-0.87(1.8)$ \\
TMT B, $z$-score & $-0.60(1.3)$ & $-0.85(1.3)$ \\
Visuoconstruction, $z$-score & $0.26(1.2)$ & $0.18(1.2)$ \\
Cognitive composite score, & $-0.63(0.7)$ & $-0.95(0.7) * * *$ \\
$\quad z$-score & & \\
APOE $\varepsilon 4$ carrier, $n(\%)$ & $42(44.2)$ & $29(67.4) * *$ \\
Hippocampal volume, cm ${ }^{3}$ & $5.7(0.7)$ & $5.3(0.6) *$ \\
A $\beta 1-42$, pg/ml & $682(309)$ & $470(145) *$ \\
T-tau, pg/ml & $409(219)$ & $686(377) *$ \\
Ratio A $\beta 1-42 / t$-tau & $2.3(1.7)$ & $0.8(0.5) *$ \\
\hline
\end{tabular}

Data are mean (SD), unless specified otherwise. Group size is different for cognitive tests, APOE, hippocampal volume, and CSF measures.

Key: A $\beta$, amyloid beta; AD, Alzheimer's disease; aMCI, amnestic mild cognitive impairment; APOE, apolipoprotein E; CSF, cerebrospinal fluid; MCI, mild cognitive impairment; MCI-AD, subjects with MCI who converted to AD-type dementia at follow-up; MCI non-AD, subjects with MCI who did not convert to AD-type dementia at follow-up; MMSE, Mini-Mental State Examination; T-tau, total tau; TMT, Trail Making Test.

$* p<0.001$ compared with MCI non-AD.

** $p<0.05$, compared with MCI non-AD.

$* * * p<0.01$, compared with MCI non-AD.

dementia at follow-up, 14 had a follow-up of less than 1.5 years. When we repeated analyses after exclusion of these subjects, results were similar.

\subsubsection{Multivariable predictors}

When both the CSF A $\beta 1-42 /$ tau ratio and HCV were entered in the same model, the markers predicted AD-type dementia independently from each other (OR CSF ratio $=$ 7.9; 95\% CI, 3.3-19; $p<0.001$; OR HCV $=2.8$; 95\% CI, $1.3-6.2 ; p=0.01)$. The combination increased the predictive accuracy relative to the model with only the CSF A $\beta 1-42 /$ tau ratio $\left(\chi^{2}=6.6 ; d f=1 ; p=0.01\right)$. Next, we tested the added diagnostic value of CSF A $\beta 1-42 /$ tau ratio and HCV compared with models with other markers that could predict AD-type dementia in the univariable analyses and age. When age, MMSE score, and APOE genotype were entered in the first step, CSF A $\beta 1-42 /$ tau ratio and $\mathrm{HCV}$ increased the predictive accuracy in the second step $\left(\chi^{2}=24.1 ; d f=2 ; p<0.001\right)$. Both markers were significant predictors $(\mathrm{OR}$ CSF ratio $=7.9 ; 95 \% \mathrm{CI}, 2.8-22 ; p<$ 0.001 ; OR HCV $=2.8 ; 95 \% \mathrm{CI}, 1.1-6.9 ; p=0.03$ ), whereas age, MMSE score, and APOE genotype no longer predicted outcome $(p>0.42)$. When we tested a multivariable model in which the cognitive composite score was entered in the first step $(p=0.012)$ and CSF A $\beta 1-42 /$ tau 
Table 2

Predictive accuracy of CSF and MRI markers for AD-type dementia after 2 years

\begin{tabular}{|c|c|c|c|c|c|c|}
\hline Markers & Sensitivity & Specificity & PPV & NPV & Youden index ${ }^{\mathrm{a}}$ & Odds ratio $^{\mathrm{b}}$ \\
\hline $\mathrm{CSF} \mathrm{A} \beta 1-42 /$ tau ratio & $0.83(0.73-0.94)$ & $0.65(0.56-0.74)$ & $0.52(0.41-0.63)$ & $0.89(0.83-0.96)$ & $0.48(0.34-0.62)$ & $9.2(3.9-22)$ \\
\hline $\mathrm{HCV}$ & $0.56(0.42-0.70)$ & $0.74(0.66-0.83)$ & $0.5(0.37-0.63)$ & $0.79(0.71-0.87)$ & $0.31(0.14-0.47)$ & $3.7(1.8-7.6)$ \\
\hline $\begin{array}{l}\text { CSF A } \beta 1-42 / \text { tau ratio or } \\
\text { HCV abnormal }\end{array}$ & $0.94(0.87-1.00)$ & $0.52(0.43-0.62)$ & $0.47(0.37-0.57)$ & $0.95(0.89-1.00)$ & $0.46(0.34-0.58)$ & $17(4.8-56)$ \\
\hline $\begin{array}{l}\text { CSF A } \beta 1-42 / \text { tau ratio and } \\
\text { HCV abnormal }\end{array}$ & $0.46(0.32-0.60)$ & $0.87(0.80-0.93)$ & $0.61(0.45-0.77)$ & $0.78(0.70-0.85)$ & $0.33(0.17-0.48)$ & $5.5(2.5-12)$ \\
\hline
\end{tabular}

Results are presented with $95 \%$ confidence intervals.

Key: A $\beta$, amyloid beta; AD, Alzheimer's disease; CSF, cerebrospinal fluid; HCV, hippocampal volume; NPV, negative predictive value; PPV, positive predictive value.

a Youden index $=($ sensitivity + specificity -1$)$.

b All $p$-values $<0.001$.

ratio and $\mathrm{HCV}$ in the second step, both biomarkers predicted AD-type dementia $(p<0.05)$ but the cognitive composite score not $(p=0.13)$ (Tables 1 and 2).

\subsubsection{Test sequence}

In further analyses, we only included the CSF and HCV measures because other covariates did not contribute to the overall predictive accuracy.

The added predictive value of the CSF A $\beta 1-42 /$ tau ratio and HCV to the other marker is presented in Supplementary Table S2, and Fig. 1. If the CSF A $\beta 1-42 /$ tau ratio was analyzed first, assessment of HCV increased predictive accuracy for AD-type dementia in subjects with a normal CSF $\mathrm{A} \beta 1-42 /$ tau ratio $(\mathrm{OR}, 7.1 ; p=0.014)$, but not in subjects with an abnormal CSF A $\beta 1-42 /$ tau ratio (OR, 2.0; $p=$ $0.13)$. If $\mathrm{HCV}$ was analyzed first, assessment of CSF $A \beta 1-$ $42 /$ tau ratio increased predictive accuracy both in subjects with normal HCV (OR, 14.4; $p<0.001)$ and with abnormal HCV (OR, $4.1 ; p=0.025)$.

A

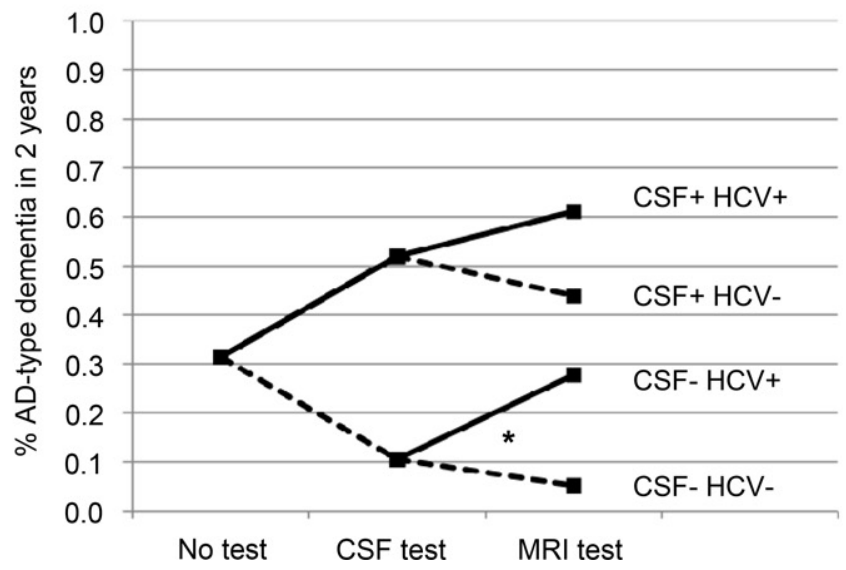

Fig. 1 shows probability plots of AD-type dementia for different sequences of CSF $\mathrm{A} \beta 1-42 /$ tau ratio and $\mathrm{HCV}$ assessment, thereby visualizing the change in AD probability after adding the results for each biomarker.

\subsection{Predictors of cognitive decline}

Although conversion to AD-type dementia after 2-year follow-up is a clinically relevant outcome measure, the potential of CSF and MRI biomarkers to identify prodromal $\mathrm{AD}$ may be underestimated as subjects may convert at longer follow-up intervals. Therefore, we additionally performed slope analyses for annual cognitive decline over the 5-year follow-up period.

\subsubsection{Univariable predictors}

The CSF A $\beta 1-42 /$ tau ratio at baseline predicted cognitive decline on the MMSE and cognitive composite score (all $p<0.001$ ), while HCV only predicted decline on the MMSE $(p<0.008$; Table 3). The CSF A $\beta 1-42 /$

B

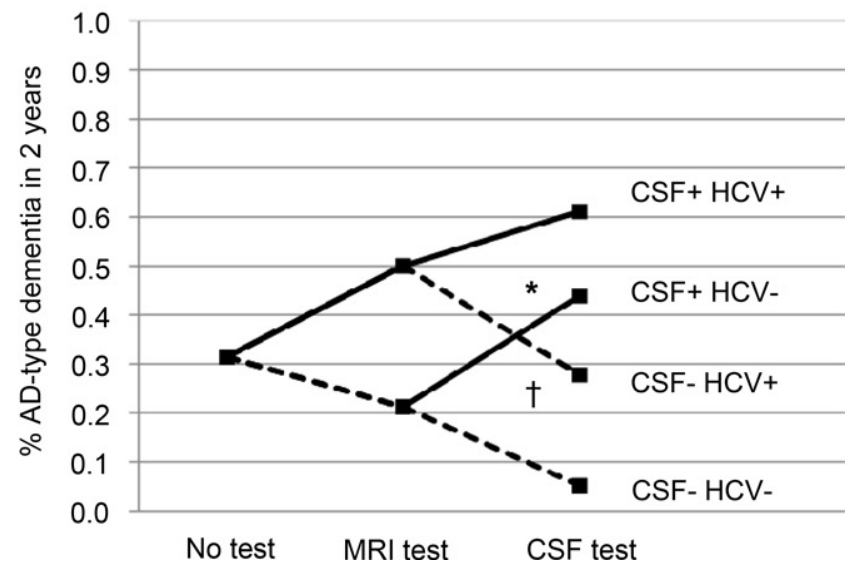

Fig. 1. Probability of Alzheimer's disease (AD)-type dementia in 2 years related to the sequence of cerebrospinal fluid (CSF) and hippocampal volume (HCV) assessment. The graph shows the change in AD probability according to biomarker scores. The starting point represents the AD conversion rate in the total mild cognitive impairment (MCI) population. Dotted lines represent negative (normal) test results and full lines represent positive (abnormal) test results. (A) First CSF assessment then HCV assessment; (B) first HCV assessment then CSF assessment. Thirty-six subjects had both abnormal CSF ratio and HCV (with 22 converters to AD-type dementia), 41 subjects had an abnormal CSF ratio and a normal HCV (18 converters), 18 subjects had a normal CSF ratio and an abnormal HCV (5 converters), 58 subjects had both a normal CSF ratio and HCV ( 3 converters). ${ }^{*} p<0.05{ }^{\dagger} p<0.001$ : difference in AD probability in 2 years between subjects with normal and abnormal biomarkers after second biomarker assessment. 
Table 3

Annual cognitive decline over 5 years of follow-up according to CSF and MRI biomarker results at baseline

\begin{tabular}{|c|c|c|c|c|}
\hline & \multicolumn{2}{|l|}{ MMSE } & \multicolumn{2}{|c|}{ Cognitive composite score } \\
\hline & Baseline score & Slope & Baseline score & Slope \\
\hline \multicolumn{5}{|c|}{$\mathrm{CSF} \mathrm{A} \beta 142 /$ tau ratio } \\
\hline Normal & $27.5(0.82)^{*}$ & $-0.28(0.13)^{* * *}, * * *$ & $-0.70(0.10)^{*}$ & $0.001(0.02)^{* * *}$ \\
\hline Abnormal & $26.6(0.83)$ & $-1.24(0.12) * * * *$ & $-0.93(0.11)$ & $-0.25(0.04)^{* * * * *}$ \\
\hline \multicolumn{5}{|l|}{$\mathrm{HCV}$} \\
\hline Normal & $27.3(0.73) * * * * *$ & $-0.61(0.13)^{* * * *}, * * * * *$ & $-0.76(0.09)$ & $-0.05(0.02)$ \\
\hline Abnormal & $26.1(0.80)$ & $-1.17(0.16) * * * *$ & $-0.89(0.11)$ & $-0.14(0.04)^{* *}$ \\
\hline
\end{tabular}

Data are mean (standard error of the mean). Slope refers to annual change on the test. A negative slope indicates cognitive decline.

Key: $\mathrm{CSF}=$ cerebrospinal fluid, $\mathrm{HCV}=$ hippocampal volume, MMSE $=$ Mini Mental State Examination

* $p<0.05$ for baseline score or slope compared with baseline score or slope in abnormal biomarker group.

** $p<0.05$, for slope different from 0 (this means a statistically significant change over time in test score).

*** $p<0.001$, for baseline score or slope compared with baseline score or slope in abnormal biomarker group.

**** $p<0.001$ for slope different from 0 (this means a statistically significant change over time in test score).

$* * * * * p<0.01$, for baseline score or slope compared with baseline score or slope in abnormal biomarker group.

tau ratio was a better predictor for decline on the MMSE compared with $\mathrm{HCV}$ (CSF $F=27.6, p<0.001$; MRI $F=7.5$, $p=0.008)$.

\subsubsection{Multivariable predictors}

Multivariable analyses were performed with decline on the MMSE as outcome, because only for this outcome measure both biomarkers predicted decline in univariable analyses. When the CSF A $\beta 1-42 /$ tau ratio was entered first, addition of HCV significantly increased the overall predictive accuracy (decrease in $-2 \mathrm{LL}=6.5 ; F=4.72 ; p=$ $0.011)$.

\subsubsection{Test sequence}

The added predictive value for decline on the MMSE of the CSF $\mathrm{A} \beta 1-42 /$ tau ratio and $\mathrm{HCV}$ to the other marker is presented in Supplementary Table S3, and Fig. 2. If the CSF A $\beta 1-42 /$ tau ratio was analyzed first, assessment of $\mathrm{HCV}$ increased predictive accuracy for cognitive decline in subjects with a normal CSF $\mathrm{A} \beta 1-42 /$ tau ratio $(p=0.001)$, but not in subjects with an abnormal CSF $A \beta 1-42 /$ tau ratio $(p>0.3)$. If HCV was analyzed first, assessment of CSF A $\beta 1-42 /$ tau ratio increased predictive accuracy both in subjects with normal HCV $(p<0.001)$ and with abnormal $\operatorname{HCV}(p=0.038)$.

\subsection{Biomarkers as inclusion criterion for prodromal $A D$ trial}

We used the different combinations of the CSF A $\beta 1-$ 42/tau ratio and HCV shown in Table 2 to select subjects with MCI for a fictive amyloid targeting AD trial with
A

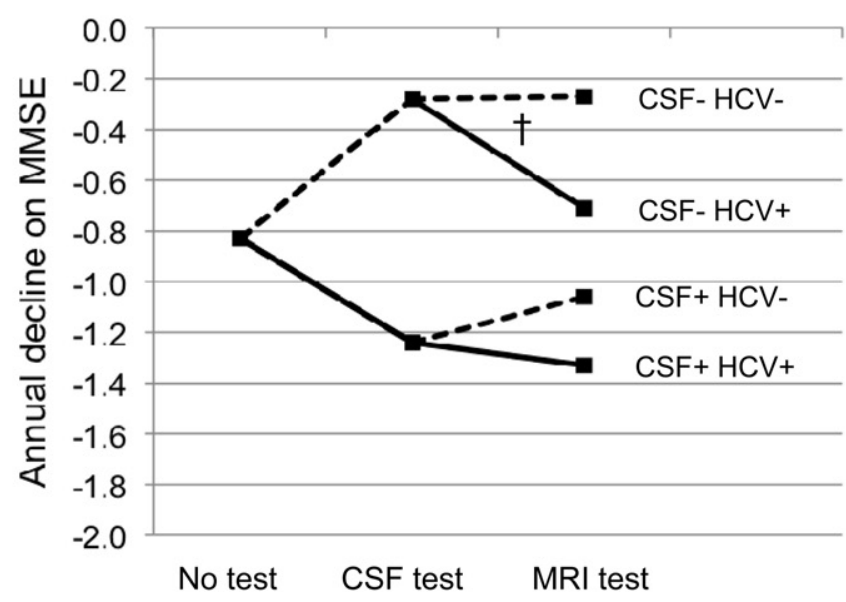

B

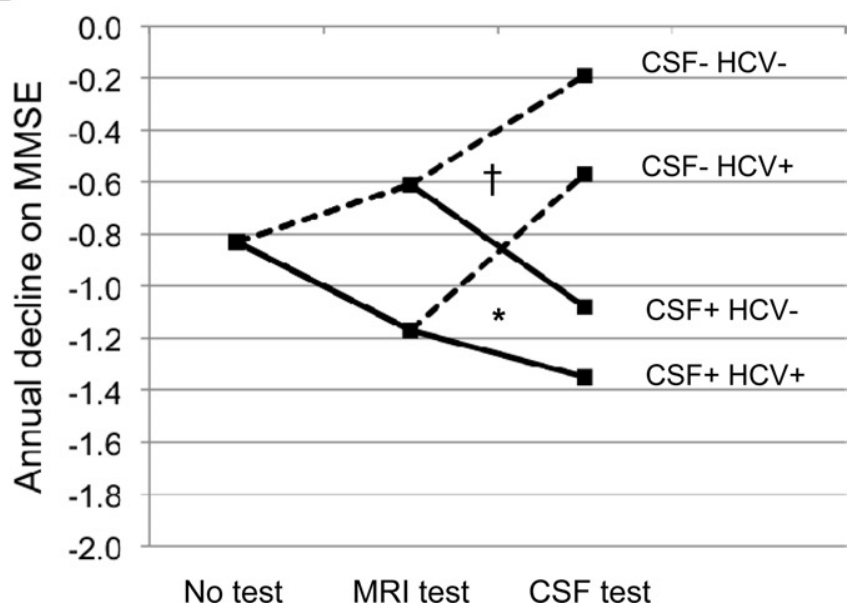

Fig. 2. Average annual cognitive decline on Mini Mental State Examination (MMSE) related to the sequence of cerebrospinal fluid (CSF) and hippocampal volume (HCV) assessment. The graph shows change in annual cognitive decline according to biomarker scores. The starting point represents the decline on MMSE in the total mild cognitive impairment (MCI) population regardless of biomarker results. Dotted lines represent negative (normal) test results and full lines represent positive (abnormal) test results. (A) First CSF assessment then HCV assessment; (B) first HCV assessment then CSF assessment. As the sample size of the subgroups was different, different slopes may be presented for the same final groups. $* p<0.05 ;{ }^{\dagger} p<0.001$ : difference in annual cognitive decline on MMSE between subjects with normal and abnormal biomarkers after second biomarker assessment. 
Table 4

Number of subjects required for $\mathrm{AD}$ trial design based on biomarker inclusion criteria

\begin{tabular}{llll}
\hline Biomarkers & $\begin{array}{l}\text { Number } \\
\text { required for } \\
\text { screening }\end{array}$ & $\begin{array}{l}\text { Sample size } \\
\text { for trial }\end{array}$ & $\begin{array}{l}\text { Screening failure } \\
\text { rate }\end{array}$ \\
\hline $\begin{array}{c}\text { CSF A } \beta 1-42 / \text { tau ratio } \\
\text { abnormal }\end{array}$ & 1761 & 880 & 0.5 \\
$\begin{array}{l}\text { HCV abnormal } \\
\text { CSF A } \beta 1-42 / \text { tau ratio }\end{array}$ & 3931 & 1376 & 0.65 \\
$\quad 228$ & 1381 & 0.38 \\
$\begin{array}{c}\text { or HCV abnormal } \\
\text { A } \beta 1-42 / \text { tau ratio }\end{array}$ & 2675 & 642 & 0.76 \\
and HCV abnormal & & &
\end{tabular}

The assumptions with regard to trial design are described in the methods section. Screening failure rate $=1$ (sample size divided by number required for screening), i.e., the proportion of subjects that were screened but not included in the $\mathrm{AD}$ trial, as they did not have abnormal biomarkers. Note that this failure rate does not take into account failure rates of CSF collection.

Key: A $\beta$, amyloid beta; AD, Alzheimer's disease; CSF, cerebrospinal fluid; HCV, hippocampal volume.

conversion to AD-type dementia after 2 years as outcome. The sample sizes, numbers required for screening, and screening failure rates varied considerably between the different combinations (Table 4). The sample size was smallest for the strategy that required both an abnormal CSF A $\beta 1-$ 42/tau ratio and abnormal $\mathrm{HCV}$ at baseline (642 vs. $880-$ 1381). The number required for screening was lowest if only the CSF $\mathrm{A} \beta 1-42 /$ tau ratio was required to be abnormal (1761 vs. 2228-3931). The screening failure rate was lowest if either the CSF $\mathrm{A} \beta 1-42 /$ tau ratio or $\mathrm{HCV}$ was required to be abnormal (38\% vs. $50 \%-76 \%$ ). The strategy that required only abnormal CSF markers had the best trade-off between sample size $(n=880)$ and number required for screening ( $n=1761$ ), as numbers were best (screening) or second best (sample size).

\section{Discussion}

We showed that the CSF A $\beta 1-42 /$ tau ratio was the best predictor for AD-type dementia at follow-up and for cognitive decline in subjects with MCI. HCV could increase the predictive accuracy of the CSF $\mathrm{A} \beta 1-42 /$ tau ratio. This increase in predictive accuracy for AD-type dementia and cognitive decline was because HCV predicted AD-type dementia and cognitive decline in subjects with a normal CSF A $\beta 1-42 /$ tau ratio.

Test sequence analyses suggested that CSF assessment should be performed first for prediction of AD-type dementia at follow-up. HCV assessment may be considered in subjects who have a normal CSF A $\beta 1-42 /$ tau ratio. A strategy in which $\mathrm{HCV}$ assessment is performed first and CSF assessment next seems less efficient as CSF assessment would further increase predictive accuracy regardless of the outcome of the HCV analysis. However, with respect to feasibility, MRI scanning may be more acceptable than CSF collection in daily practice. MRI is often already routinely done to exclude other diseases. Still, volumetric assessment of the hippocampus is not widely available.

Furthermore, the current study showed that for a fictive AD trial targeting amyloid pathology in subjects with MCI, subjects could be best selected based on CSF biomarkers because this provided the best balance between sample size and number of subjects required for screening. Still, the sample size was smaller if both CSF A $\beta 1-42 /$ tau ratio and $\mathrm{HCV}$ were required to be abnormal. However, the screening failure rate was very high for this combination, which may limit its clinical utility. The screening failure rate was lowest if subjects were required to have either an abnormal CSF A $\beta 1-42 /$ tau ratio or an abnormal HCV. A disadvantage of this approach was the much higher sample size compared with that of the selection based on an abnormal CSF A $\beta 1-$ 42/tau ratio alone. Selection based on an abnormal HCV alone was least efficient because both the number required for screening and sample size were among the highest of the 4 approaches. This may be partly because the fictive trial was designed for targeting amyloid pathology such that only subjects with an abnormal CSF A $\beta 1-42 /$ tau ratio were supposed to respond to therapy.

This is the first large-scale multicenter study conducted in a memory clinic setting of subjects classified according to a broad definition of MCI, including aMCI (68\%) and naMCI that compared CSF and MRI markers for prediction of cognitive decline. Our study corroborates the findings of studies of subjects with aMCI (Ewers et al., 2010; Heister et al., 2011; Vemuri et al., 2009), that the combination of the CSF ratio and measure of medial temporal lobe atrophy predicted AD-type dementia better than each biomarker alone. This also confirms the findings of smaller singlecenter studies performed in subjects with MCI (Bouwman et al., 2007; Eckerström et al., 2010; Galluzzi et al., 2010). It validates the use of biomarkers for prediction of AD-type dementia in subjects who meet the criteria of a broad definition of MCI, including aMCI and naMCI. This supports the new NIA-AA criteria for MCI due to AD, which uses a broad definition of MCI as well (Albert et al., 2011). The conversion rate of $31 \%$ to $\mathrm{AD}$-type dementia after 2 years in the present study is comparable to conversion rates in previous studies with a similar follow-up period (Eckerström et al., 2010; Galluzzi et al., 2010; Vemuri et al., 2009).

The overall predictive accuracy (OR) for AD-type dementia of the CSF A $\beta 1-42 /$ tau ratio was twice as high as that of the HCV. This was mainly due to the higher sensitivity of the CSF $\mathrm{A} \beta 1-42 /$ tau ratio compared with that of the HCV (Table 2). This is in line with the hypothetical dynamic model of AD biomarkers (Jack et al., 2010), stating that CSF biomarkers become abnormal at an earlier stage than MRI biomarkers. We also found that the specificity of the HCV was higher than that of the CSF A $\beta 1-42 /$ tau ratio. This may be considered unexpected as medial temporal lobe atrophy is not specific for AD and also observed in other neurodegenerative and vascular disorders. However, the 
higher specificity of the $\mathrm{HCV}$ could also be explained by the hypothetical dynamic model of AD biomarkers. As CSF markers are expected to become abnormal before the HCV (Jack et al., 2010), there will be more MCI subjects with prodromal $\mathrm{AD}$ with an abnormal CSF $\mathrm{A} \beta 1-42 /$ tau ratio who have not yet converted to AD-type dementia within 2 years than there will be MCI subjects with prodromal $\mathrm{AD}$ with an abnormal $\mathrm{HCV}$ who have not yet converted to AD-type dementia within 2 years.

Test sequence analyses revealed the presence of a small group of subjects ( $n=18,12 \%$ of the total sample) with a normal CSF A $\beta 1-42 /$ tau ratio but abnormal HCV and a conversion rate of $28 \%$ to $\mathrm{AD}$-type dementia after 2 years. This is an interesting group because it is not in line with the hypothetical dynamic model of AD biomarkers (Jack et al., 2010), as abnormal CSF biomarkers did not precede medial temporal lobe atrophy. Further research is needed to investigate whether these subjects have an atypical presentation of $\mathrm{AD}$ or whether they are misclassified cases either because of the applied cutoffs or because $\mathrm{AD}$ is not the cause of the dementia.

MMSE score, a cognitive composite score, and APOE genotype predicted AD-type dementia in univariable analyses, however, in the combined model with CSF and MRI markers, these variables were no longer significant predictors. This indicates that CSF and MRI can be used independent of cognitive scores and APOE genotype for short-term prediction of AD-type dementia. Nevertheless, our findings are inconsistent with some previous studies of subjects with aMCI. One study showed that MRI and APOE genotype did not significantly add to the predictive accuracy of neuropsychological tests (Fleisher et al., 2008). Another study found that the optimal biomarker combination and neuropsychological tests were equally predictive for AD-type dementia (Ewers et al., 2010). The more severely impaired cohort that was used in the former study and the inclusion of only subjects with aMCI in both studies could explain the inconsistent findings.

Although a 2-year follow-up is clinically relevant, the potential of CSF and MRI biomarkers to identify prodromal AD may be underestimated (Aisen et al., 2011). Therefore, we also performed slope analyses for annual cognitive decline over 5 years. These analyses yielded very similar findings as our analysis on conversion to AD-type dementia after 2 years. The CSF A $\beta 1-42 /$ tau ratio predicted annual cognitive decline better than $\mathrm{HCV}$. In the sequence analysis with decline on MMSE as outcome, HCV increased predictive accuracy only in subjects with a normal CSF A $\beta 1-42 /$ tau ratio but not in subjects with an abnormal ratio, while the CSF $A \beta 1-42 /$ tau ratio improved predictive accuracy regardless of $\mathrm{HCV}$. The lower predictive accuracy of $\mathrm{HCV}$ can again in part be explained by a lower sensitivity of this marker for prodromal AD. This is supported by the observation that decline in subjects with a normal $\mathrm{HCV}$ is higher than in subjects with a normal CSF ratio in Table 3 . This higher decline is probably driven by subjects with an abnormal CSF ratio among subjects with a normal HCV.

This study had several limitations. As the findings were based on memory clinic populations, they may not be generalized to other settings, including the general population. Furthermore, the cutoffs of the CSF A $\beta 1-42 /$ tau ratio and $\mathrm{HCV}$ were determined within a study population that also included the subjects from the present analyses. Although this may have led to an overestimation of the predictive accuracy of the biomarkers, it is unlikely that it influences our findings with respect to the differences in predictive accuracy between the CSF A $\beta 1-42 /$ tau ratio and $\mathrm{HCV}$, as we used the same method to define the cut point for each biomarker. We defined cutoffs regardless of age, although biomarkers may change with age. However, when we repeated analyses using age-adjusted cutoffs ( $\leq 70$ vs. $>70$ years) analyses yielded similar findings. In addition, there was variability in scanners used, which may have influenced the volumetric measurements and predictive accuracy of the HCV. However, the LEAP approach has been shown to be robust for scanner variability (Wolz et al., 2010). The follow-up period to AD-type dementia was relatively short but for clinical trials short-term prognosis may be important. However, we used a longer follow-up period to investigate the predictive accuracy of CSF and MRI biomarkers for annual cognitive decline over 5 years. Moreover, the diagnosis of AD-type dementia at follow-up was not neuropathologically validated. This may have led to the misclassification of some cases.

A major strength of this study was the large sample size. The overall multicenter design favors generalizability to other memory clinic settings, although a considerable amount of subjects was recruited from 1 single center. Furthermore, this is the first study of predictive accuracy of the combination of CSF and MRI markers for AD-type dementia and cognitive decline that investigated the test sequence of CSF and HCV assessments in an unselected population with subjects classified according to a broad definition of MCI.

In sum, test sequence analyses may lead to cost reduction and to a decrease in patients' burden. Future research is needed to evaluate the ratio of costs and effectiveness for patients regarding biomarker assessment, as this may eventually require adjustments to patient policy.

Also the combination of CSF and MRI biomarkers with Pittsburgh compound B (PIB)-positron emission tomography (PET), and fluorodeoxyglucose (FDG) PET should be investigated, because this may further aid to define an algorithm of markers for the accurate prediction of AD-type dementia in subjects with MCI. While hippocampal atrophy and CSF markers are given equal diagnostic accuracy in recent criteria for prodromal $\mathrm{AD}$ or $\mathrm{MCI}$ due to $\mathrm{AD}$, our findings suggest that this may not be the case and a CSF A $\beta 1-42 /$ tau ratio may be preferred over HCV assessment because of its higher sensitivity. 


\section{Disclosure statement}

Dr. Burns and Dr. L' Italien are employees of BristolMyers Squibb. Dr. Scheltens serves/has served on the advisory boards of: Genentech, Novartis, Roche, Danone, Nutricia, Baxter and Lundbeck. He has been a speaker at symposia organized by Lundbeck, Merz, Danone, Novartis, Roche and Genentech. For all his activities he receives no personal compensation. He serves on the editorial board of Alzheimer's Research and Therapy and Alzheimers Disease and Associated Disorders, is a member of the scientific advisory board of the EU Joint Programming Initiative and the French National Plan Alzheimer. Dr. Tsolaki serves on scientific advisory boards for Novartis, Pfizer, and Iasis. Dr. Minthon serves on advisory boards for Pfizer, Sweden. Dr. Teunissen serves as a member of the scientific advisory board of Innogenetics SA. Dr. Barkhof has received consulting fees or honoraria from UCB, Bayer Schering, Sanofi-Aventis, Novartis, Roche, Merck-Serono, Synthon BV, Janssen Research, Lundbeck, Biogen-Idec, and is a member of UCB, Bayer Schering, Sanofi-Aventis, Novartis, and Roche advisory boards. Dr. Blennow has served on advisory boards for Innogenetics, Ghent, Belgium. Dr. Wolz is consultant for IXICO. Dr. Rueckert is founder and consultant for IXICO. Dr. Visser has served as an advisory board member of Myriad, Guidage study Ipsen, and BristolMyers Squibb. The remaining authors disclose no conflicts.

The medical ethics committee at each center approved the study. All patients provided informed consent.

\section{Acknowledgements}

The DESCRIPA study was supported by European Community's 5th Framework Programme contract number QLK-6-CT-2002-02455. Additional funding was provided by the Center for Translational Molecular Medicine (www. ctmm.nl) project LeARN (grant 02N-01; SV, RH), BristolMyers Squibb, and the European Community's 7th Framework Programme (FP7/2007-2013), grant agreement no 211696 (Lipididiet [IvR]), and grant agreement no 224328 (PredictAD [RW, DR]). The Alzheimer Center VUmc receives unrestricted funding from various sources through the VUmc Fonds.

\section{Appendix A. Supplementary data}

Supplementary data associated with this article can be found, in the online version, at doi:10.1016/j.neurobiolaging.2011.12.017.

\section{References}

Aisen, P.S., Andrieu, S., Sampaio, C., Carrillo, M., Khachaturian, Z.S., Dubois, B., Feldman, H.H., Petersen, R.C., Siemers, E., Doody, R.S., Hendrix, S.B., Grundman, M., Schneider, L.S., Schindler, R.J., Salmon, E., Potter, W.Z., Thomas, R.G., Salmon, D., Donohue, M., Bednar, M.M., Touchon, J., Vellas, B., 2011. Report of the task force on designing clinical trials in early (predementia) AD. Adv. Neurol. 76, $280-286$.

Albert, M.S., DeKosky, S.T., Dickson, D., Dubois, B., Feldman, H.H., Fox, N.C., Gamst, A., Holtzman, D.M., Jagust, W.J., Petersen, R.C., Snyder, P.J., Carrillo, M.C., Thies, B., Phelps, C.H., 2011. The diagnosis of mild cognitive impairment due to Alzheimer's disease: recommendations from the National Institute on Aging-Alzheimer's Association workgroups on diagnostic guidelines for Alzheimer's disease. Alzheimers Dement. 7, 270-279.

American Psychiatric Association, 1994. Diagnostic and Statistical Manual of Mental Disorders, fourth ed. American Psychiatric Association, Washington DC.

Andreasen, N., Hesse, C., Davidsson, P., Minthon, L., Wallin, A., Winblad, B., Vanderstichele, H., Vanmechelen, E., Blennow, K., 1999. Cerebrospinal Fluid Beta-Amyloid(1-42) in Alzheimer Disease: Differences Between Early- and Late-Onset Alzheimer Disease and Stability During the Course of Disease. Arch. Neurol. 56, 673-680.

Blennow, K., Hampel, H., 2003. CSF markers for incipient Alzheimer's disease. Lancet Neurol. 2, 605-613.

Blennow, K., Wallin, A., Agren, H., Spenger, C., Siegfried, J., Vanmechelen, E., 1995. Tau protein in cerebrospinal fluid: a biochemical diagnostic marker for axonal degeneration in Alzheimer's disease? Mol. Chem. Neuropathol. 26, 231-245.

Bouwman, F.H., Schoonenboom, S.N., van der Flier, W.M., van Elk, E.J., Kok, A., Barkhof, F., Blankenstein, M.A., Scheltens, P., 2007. CSF biomarkers and medial temporal lobe atrophy predict dementia in mild cognitive impairment. Neurobiol. Aging 28, 1070-1074.

Devanand, D.P., Pradhaban, G., Liu, X., Khandji, A., De Santi, S., Segal, S., Rusinek, H., Pelton, G.H., Honig, L.S., Mayeux, R., Stern, Y., Tabert, M.H., de Leon, M.J., 2007. Hippocampal and entorhinal atrophy in mild cognitive impairment: Prediction of Alzheimer disease. Neurology 68, 828-836.

Eckerström, C., Andreasson, U., Olsson, E., Rolstad, S., Blennow, K., Zetterberg, H., Malmgren, H., Edman, A., Wallin, A., 2010. Combination of Hippocampal Volume and Cerebrospinal Fluid Biomarkers Improves Predictive Value in Mild Cognitive Impairment. Dement. Geriatr. Cogn. Disord. 29, 294-300.

Ewers, M., Walsh, C., Trojanowski, J.Q., Shaw, L.M., Petersen, R.C., Jack, C.R., Feldman, H.H., Bokde, A.L.W., Alexander, G.E., Scheltens, P., Vellas, B., Weiner, M., Hampel, H., 2010. Prediction of conversion from mild cognitive impairment to Alzheimer's disease dementia based upon biomarkers and neuropsychological test performance. Neurobiol. Aging, 2010. Doi: 10.1016/j.neurobiolaging.2010.10.019.

Fleisher, A.S., Sun, S., Taylor, C., Ward, C.P., Gamst, A.C., Petersen, R.C., Jack, C.R., Aisen, P.S., Thal, L.J., 2008. Volumetric MRI vs clinical predictors of Alzheimer disease in mild cognitive impairment. Neurology 70, 191-199.

Galluzzi, S., Geroldi, C., Ghidoni, R., Paghera, B., Amicucci, G., Bonetti, M., Zanetti, O., Cotelli, M., Gennarelli, M., Frisoni, G.B., Translational Outpatient Memory Clinic Working Group, 2010. The new Alzheimer's criteria in a naturalistic series of patients with mild cognitive impairment. J. Neurol. 257, 2004-2014.

Geroldi, C., Rossi, R., Calvagna, C., Testa, C., Bresciani, L., Binetti, G., Zanetti, O., Frisoni, G.B., 2006. Medial temporal atrophy but not memory deficit predicts progression to dementia in patients with mild cognitive impairment. J. Neurol. Neurosurg. Psychiatry 77, 12191222.

Hampel, H., Wilcock, G., Andrieu, S., Aisen, P., Blennow, K., Broich, K., Carrilo, M., Fox, N.C., Frisoni, G.B., Isaac, M., Lovestone, S., Nordberg, A., Prvulovic, D., Sampaio, C., Scheltens, P., Weiner, M., Winblad, B., Coley, N., Vellas, B., 2011. Biomarkers for Alzheimer's disease therapeutic trials. Prog. Neurobiol. 95, 579-593.

Hansson, O., Zetterberg, H., Buchhave, P., Londos, E., Blennow, K., Minthon, L., 2009. Association between CSF biomarkers and incipient Alzheimer's disease in patients with mild cognitive impairment: a follow-up study. Lancet Neurol. 5, 228-234. 
Heagerty, P.J., Lumley, T., Pepe, M.S., 2000. Time-Dependent ROC Curves for Censored Survival Data and a Diagnostic Marker. Biometrics 56, 337-344.

Heister, D., Brewer, J.B., Magda, S., Blennow, K., McEvoy, L.K., Alzheimer's Disease Neuroimaging Initiative, 2011. Predicting MCI outcome with clinically available MRI and CSF biomarkers. Neurology $77,1619-1628$.

Herukka, S.K., Hallikainen, M., Soininen, H., Pirttilä, T., 2005. CSF Abeta42 and tau or phosphorylated tau and prediction of progressive mild cognitive impairment. Neurology 64, 1294-1297.

Isaac, M., Vamvakas, S., Abadie, E., Jonsson, B., Gispen, C., Pani, L., 2011. Qualification opinion of novel methodologies in the predementia stage of Alzheimer's disease: cerebro-spinal-fluid related biomarkers for drugs affecting amyloid burden-regulatory considerations by European Medicines Agency focusing in improving benefit/risk in regulatory trials. Eur. Neuropsychopharmacol. 21, 781-788.

Jack, C.R., Knopman, D.S., Jagust, W.J., Shaw, L.M., Aisen, P.S., Weiner, M.W., Petersen, R.C., Trojanowski, J.Q., 2010. Hypothetical model of dynamic biomarkers of the Alzheimer's pathological cascade. Lancet Neurol. 9, 119-128.

Jack, C.R., Petersen, R.C., Xu, Y.C., O’Brien, P.C., Smith, G.E., Ivnik, R.J., Boeve, B.F., Waring, S.C., Tangalos, E.G., Kokmen, E., 1999. Prediction of AD with MRI-based hippocampal volume in mild cognitive impairment. Neurology 52, 1397-1403.

Kolen, M., Brennan, R., 1995. Test Equating: Methods and Practices. Springer-Verlag, New York.

Landau, S.M., Harvey, D., Madison, C.M., Reiman, E.M., Foster, N.L., Aisen, P.S., Petersen, R.C., Shaw, L.M., Trojanowski, J.Q., Jack, C.R., Weiner, M.W., Jagust, W.J., Alzheimer's Disease Neuroimaging Initiative, 2010. Comparing predictors of conversion and decline in mild cognitive impairment. Neurology 75, 230-238.

Mattsson, N., Zetterberg, H., Hansson, O., Andreasen, N., Parnetti, L., Jonsson, M., Herukka, S.K., van der Flier, W.M., Blankenstein, M.A., Ewers, M., Rich, K., Kaiser, E., Verbeek, M., Tsolaki, M., Mulugeta, E., Rosén, E., Aarsland, D., Visser, P.J., Schröder, J., Marcusson, J., de Leon, M., Hampel, H., Scheltens, P., Pirttilä, T., Wallin, A., Jönhagen, M.E., Minthon, L., Winblad, B., Blennow, K., 2009. CSF biomarkers and incipient Alzheimer disease in patients with mild cognitive impairment. JAMA 302, 385-393.

McKhann, G., Drachman, D., Folstein, M., Katzman, R., Price, D., Stadlan, E.M., 1984. Clinical diagnosis of Alzheimer's disease: report of the NINCDS-ADRDA Work Group under the auspices of Department of Health and Human Services Task Force on Alzheimer's Disease. Neurology 34, 939-944.

Petersen, R.C., 2004. Mild cognitive impairment as a diagnostic entity. J. Intern. Med. 256, 183-194.
R Development Core Team, 2009. R: A language and environment for statistical computing. R Foundation for Statistical Computing, Vienna.

Severens, J.L., Sonke, G., Laheij, R.J., Verbeek, A.L., De Vries Robbé, P.F., 2001. Efficient diagnostic test sequence: Applications of the probability-modifying plot. J. Clin. Epidemiol. 54, 1228-1237.

Shaw, L.M., Vanderstichele, H., Knapik-Czajka, M., Clark, C.M., Aisen, P.S., Petersen, R.C., Blennow, K., Soares, H., Simon, A., Lewczuk, P., Dean, R., Siemers, E., Potter, W., Lee, V.M., Trojanowski, J.Q., the Alzheimer's Disease Neuroimaging Initiative, 2009. Cerebrospinal fluid biomarker signature in Alzheimer's Disease Neuroimaging Initiative subjects. Ann. Neurol. 65, 403-413.

van de Pol, L.A., Verhey, F., Frisoni, G.B., Tsolaki, M., Papapostolou, P., Nobili, F., Wahlund, L., Minthon, L., Frölich, L., Hampel, H., Soininen, H., Knol, D.L., Barkhof, F., Scheltens, P., Visser, P.J., 2009. White matter hyperintensities and medial temporal lobe atrophy in clinical subtypes of mild cognitive impairment: the DESCRIPA study. J. Neurol. Neurosurg. Psychiatry 80, 1069-1074.

van Rossum, I.A., Vos, S., Handels, R., Visser, P.J., 2010. Biomarkers as Predictors for Conversion from Mild Cognitive Impairment to Alzheimer-Type Dementia: Implications for Trial Design. J. Alzheimers Dis. 20, 881-891.

Vemuri, P., Wiste, H.J., Weigand, S.D., Shaw, L.M., Trojanowski, J.Q., Weiner, M.W., Knopman, D.S., Petersen, R.C., Jack, C.R., Alzheimer's Disease Neuroimaging Initiative, 2009. MRI and CSF biomarkers in normal, MCI, and AD subjects: Predicting future clinical change. Neurology 73, 294-301.

Visser, P.J., Verhey, F.R.J., Boada, M., Bullock, R., De Deyn, P.P., Frisoni, G.B., Frölich, L., Hampel, H., Jolles, J., Jones, R., Minthon, L., Nobili, F., Olde Rikkert, M., Ousset, P.J., Rigaud, A.S., Scheltens, P., Soininen, H., Spiru, L., Touchon, J., Tsolaki, M., Vellas, B., Wahlund, L.O., Wilcock, G., Winblad, B., 2008. Development of screening guidelines and clinical criteria for predementia Alzheimer's disease. The DESCRIPA Study. Neuroepidemiology 30, 254-265.

Visser, P.J., Verhey, F.R.J., Hofman, P.A.M., Scheltens, P., Jolles, J., 2002. Medial temporal lobe atrophy predicts Alzheimer's disease in patients with minor cognitive impairment. J. Neurol. Neurosurg., Psychiatry 72, 491-497.

Visser, P.J., Verhey, F., Knol, D.L., Scheltens, P., Wahlund, L.O., FreundLevi, Y., Tsolaki, M., Minthon, L., Wallin, A.K., Hampel, H., Bürger, K., Pirttila, T., Soininen, H., Rikkert, M.O., Verbeek, M.M., Spiru, L., Blennow, K., 2009. Prevalence and prognostic value of CSF markers of Alzheimer's disease pathology in patients with subjective cognitive impairment or mild cognitive impairment in the DESCRIPA study: a prospective cohort study. Lancet Neurol. 8, 619-627.

Wolz, R., Aljabar, P., Hajnal, J.V., Hammers, A., Rueckert, D., Alzheimer's Disease Neuroimaging Initiative, 2010. LEAP: Learning embeddings for atlas propagation. Neuroimage 49, 1316-1325. 